\title{
El hígado graso en el Kwashiorkor
}

\author{
DRES. HERNANDO FLORES *, ANNE SEAKINS ** y FERNANDO MONCKEDERG *.
}

Una de las características más riotables de la desnutrición proteica Infantil (Kwashiorkor) es la hepatomegalia debido a la infiltración grasa del hígado. Este es un signo comúnmente utilizado para diferenciat el kwashiorkor del otro tipo de desnutricion Infantil, marasmo.

EI 50 o más por ciento del peso húmedo del hígado puede ser grasa en el kwashiorkor. Aun que el contenido lipídico del hígado ha sido examinado químicamente sólo en contadas ocasiones, hay acuerdo universal en que el exceso de lípidos hepáticos está constituido prácticamente en su totalidad pro triglicéridos. Utilizando una adaptación para micro-cantidades de un método para determinar triglicéridos (1) pudimos establecer que, en efecto éstos constituyen prácticamente toda la grasa hepática en nifios con kwashiorkor (Tabla 1).

Se han eleborado diversas hipótesis para explicar patogénesis del hígado graso en el kwashiorkor. Es notable que las observaciones de los distintos investigadores son bastantes similares, a pesar de lo cual las conclusiones sacadas de estos mismos datos son muy diferentes.

Bronte-Stewar (2) sugirió que uno de los factores principales en la infiltración grasa del hígado sería una deficiencia de ácidos grasos esenciales. Schendel y Hansen (3) observaron que, en efecto, en el plasma de pacientes de kwashiorkor en recuperación había un patrón de ácidos grasos reminiscente de la deficiencia de ácidos grasos esenciales, pero interpretaron este dato como el resultado de la gran demanda producida por el gran aumento en las necesidades de transporte de lípidos que se produce durante la recuperación del

\footnotetext{
* Deartamenta de Nutrición y Tecnología de los Alimentos Sede Sur, Universidad de Chile. a* Troicat Metabolism Research Unit, University of the West
Indics, Mona, Kingston 7, Jamaica.
}

kwashiorkor. Esta jnterpretación cstá en acuerdo con un estudio posterior de Macdonald y col. (4).

Una de las primeras posibilidades en ser considerada fue la de una deficiencia específica de factores lipotrópicos. Waterlow (5) introdujo colina, metionina o inositol como suplementos en la dicta de niños con kwashiorkor en tratamiento. Los agentes lipotrópicos no tuvieron efecto beneficioso alguno. Posteriormente se ha comprobado que la concentración de fosfolípidos en el hígado, si se descuenta el efecto diluyente del exceso de triglicéridos, es normal en pacientes con kwashiorkor (6).

Además, la concentración de fosfolípidos plasmáticos en estos pacientes está sólo levemente disminuida, y su alza con el tratamiento es de importancia secundaria $(4,7-10)$.

Lewis y colaboradores (8) postularon que el exceso de grasa hepática proviene de los tejidos de depósito, basados fundamentalmente en la obscrvación de niveles muy altos de ácidos grasos

TA B L A 1

COMPARACION ENTRE EL CONTENIDO DE LIPIDOS TOTALES Y DE TRIGLICERIDOS EN BIOSIAS DE HIGADO DE NINOS CON KWASHIORKOR.

\begin{tabular}{lcc}
\hline Pacientes & $\begin{array}{c}\text { Lipidos hepúticos, } \mathrm{mg} / \mathrm{g} \\
\text { Triglicéridos }\end{array}$ & Totales \\
\hline A.C. & 505 & 487 \\
E. G. & 271 & 349 \\
I. B. & 301 & 268 \\
L. T. & 355 & 196 \\
A. Q. & 419 & 340 \\
\hline
\end{tabular}


libres en el plasma de pacientes con kwashiorkor. La evidencia de estos niveles elevados es, en efecto, muy abundante y consistente $(8,11-15)$.

Sin embargo, en nuestros pacientes, seleccio. rados entre niños con kwashiorkor sin complicaciones, cl nivel de ácidos grasos libres plasmáticos fue iormal $(9,16)$. En lá literatura es frecuente encentrar que los pacientes con kwashiorkor tienen vómitos y diarreas como signos acompañantes del sindrome. Crecmos que el stress y ayuno físiológico que ambos producen pueden explicat in elevación de acidos grasos libres observada por otros autores, que no necesita estar necesariamente asociada con el kwashiorkor.

La observación de Lewis y colaboradores (8) de que el nivel de ácidos grasos libres plasmáticos retirna rápidamente a valores normales ai administrar almidones o sacarosa, pero no proteínas, provee más evidencia en este sentido.

Como ya dijimos, la principal fracción lípídica acumulada en el húgado en el kwashiorkor es triglicéridos. Puede cntonces enfocarse el problema desde el punto de vista del metabolismo de estos ésteres. Estc enfoque es cl que hemos utilizado en una primera aproximación.

Una de las alteraciones del metabolismo de lípidos mcjor documentadas en el kwashiorkor e. la marcada hipotrigliceridemia que se observa en pacientes no tratados $(4,7-10), 16)$. También hay abundante evidencia de que inmediatamente de iniciado el tratamiento hay un alza dramática de los niveles de triglicéridos circulantes, a valores mayores que los normales $(4,7-10,16-19)$. Esta alza, por su rapidez y magnitud, llevó a Schwartz y Dean ( 7 ) a postular que las deficiencias nutricionales que conducen al kwashiorkor producen también un bloqueo de la sálida de lípidos desde el hígado. Esta es, precisamente, la hipótesis de mayor aceptación en la actualidad puesto que prácticamente toda la evidencia obtenida con postericridad a la observación de Schwartz y Dean tiende a apoyarla. A pesar de la diversidad de hipótesis ofrecidas para explicar el meconismo del hígado graso, la incapacidad relativa del higado para deshacerse de los triglicéridos es sugerida siempre como un factor contributorio $(3,8,11)$.

Waterlow (5) obiuvo evidencia indirecta de que al ractor dictario responsable del desengrasamicnto hepático durante el tratamiento es proteína. $Y$ Lewis y colaboradores (8) demostraron que ics cumbios en los niveles de triglicéridos circulantes no ocurren hasta qae se introduce proteínà en la dieta.

La principal vía metabólica de los triglicéridos circulantes antes del tratamiento como del alza de diches niveles durante la recuperación $(9,16-19)$, un hecho que lia sido confirmado empleando otro método de análisis de lipoprotcínas plismáticas (10). L.t hipótesis planteada es, entonces, que el alza en triglicéridos plasmáticos durante el tratamicsto indica desengrasamiento hepático. Medianto la determinación química de lípidos hepáticos antes y después del alza de triglicéridos circulantes cartetcristica del tratamiento del kwashiorkor hemos podido comprobar que, efectivamente, hay una disnninución de un $50 \%$ en el nivel de lípidos hepáticos durante este periodo (Figura 1). La importancia de esta observación radica en que podría utilizarse esta respuesta de los triglicéridos circulantes como indicador de la evolución del sindrome durante el tratamiento, dada su rapidez y sensibilidad.

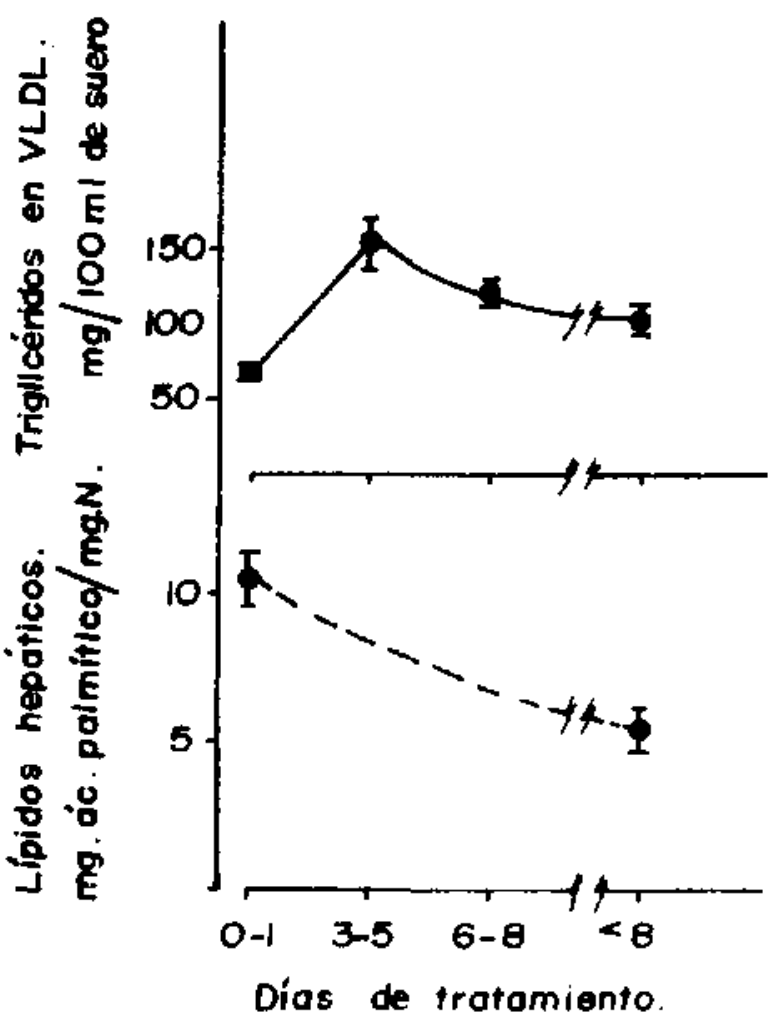

Figura 1.- Cortelación sntre los cambios en la concentración de triplice.j los en la lipoproleína sérica de muy baja densidad y en el tijads: durante la recuperacion del kwashiorkor. Adiptado de Re[. lo, cortesia del Editor Br. J. Nutr.

En experimentos "in vitro", con hígados de rata perfundidos, Heimberg y colaboradores (20) observaron que los componentes de la lipoproteína de densidad menor que 1,019 , que incluye VLDL, se liberan al líquido de perfusión guardando una proporción constante. Sobre esta base, los autores propusieron que el bloqueo de la síntesis de cualquiera de los componentes de la lipoproteína (proteína, fosfolípidos, colesterol, éstercs de colesterol) produce un bloqueo en la síntesis de esta misma, y por ende, hígado graso.

$\mathrm{H}_{\text {ay }}$ pocos estudios acerca de la composición de VLDL humana. Durante la recuperación del 
kwashiorkor hemos observado que la proporción de triglicéridos, fosfolípidos y colesterol en la fracción de lipoproteúnas de densidad menor que 1.063 es bastante constante (16). Por otro lado, Schonfeld (21) ha encontrado que durante la inducción por carbohidratos en pacientes con hiperlipemia hay un alza en la razón triglicéridos-proteina en la fracción VLDL, indicando que la lipoproteína puede tener una sobrecarga de triglicêridos. En un estudio reciente más extensivo analizamos la composición de VLDL obtenida de plasma de adultos normales bajo diferentes regímenes dietarios, de niños con kwashiorkor antes, durante y después del tratamicnto y de niños recuperados de desnutrición consumiendo dietas de diferente contenido graso, y encontramos una notable constancia en la proporción de los componentes, incluyendo proteína (Figura 2). Más aún, los datos de Schonfeld
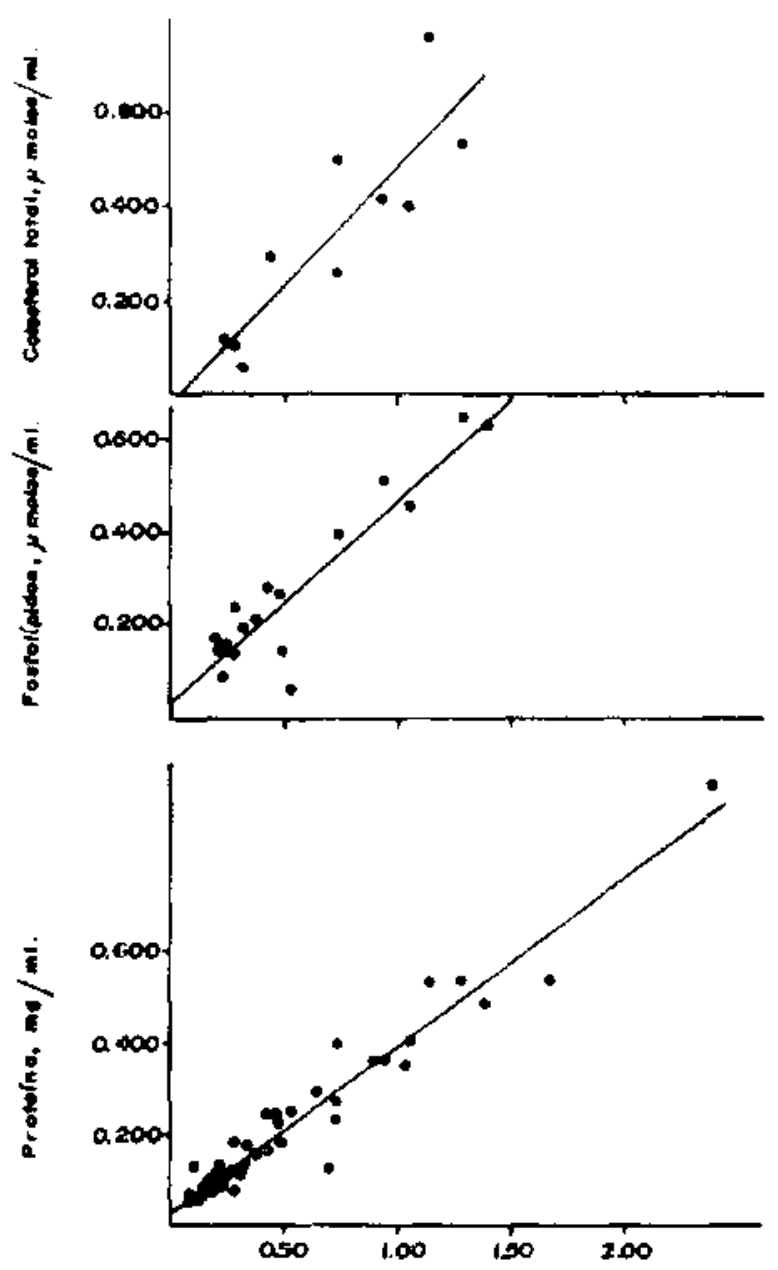

Triglicéridos, $\mu$ moles $/ \mathrm{ml}$

Figuri 2.- Corrclación entre la cunctontración de los diversos compunentes de la lipoproteína sérica de muy baja densidad. Las muestras fueron obtevidas de niños con desnutricion proteica (kwashiorkor) en diversas elapas de sL recuperación, asf como de sujelos normales. obtenitos alc individuos normales calzan sorprendentemente bien en nuestras ecuaciones de regresión. Parece entonces que, si exceptuamos a los pacientes con hiperlipemia, VLDL se comporta como una entidad química definida, y la proposición de Heimberg y colaboradores (20) sería aplicable también a humanos. Esta evidencia vilida la hipótesis de que en el kwashiorkor el defecto está a nivel de la síntesis del apopeptido de la VLDL (16). Esta hipótesis se basó en la idea generalmente aceptada de que Ia etiología dietatia del kwashiorkor en una muy baja ingesta proteica y en la asociación observada entre la presencia de hígado graso y niveles muy bajos de beta globulina parece contencr lá apoproteína circulante de VLDL (22) descrita por Roheim y colaboradores (23).

No parece factible obtener mayores evidencias acerca del mecanismo propuesto a partir de observaciones o experimentación en humanos. Por ello decidimos intentar la obtención de un modelo animal adecuado para experimentación. A pesar de que en general la rata es considerada un muy mal sustrato para la producción de signos similares al kwashiorkor, no había en la literatura referencia a la litilización de otras que ratas adultas, de 200 o más gramos de peso al momento de iniciar la depleción proteica. En estas condiciones es, efectivamente, muy difícil obtener signos reales de carencia de proteínas, presumiblemente porque en el animal adulto la gran masa proteína nusscular actúa como reserva, impidiendo una real depleción a nivel de órganos como el hígado. Razonando de esta forma, tuvimos éxito en la vbtención de una rata depletada de proteínas con signos de todo similares al kwashiorkor en niños, por cl sencillo expediente de utilizar ratas al momento del destete, o algo más jóvenes (24). En un vlazo de 8 días las ratas ya tenían hígado graso, hipoproteinemia, hipotrigliceridemia, evidencias de edema y de lesiones carenciales específicas, a pesar do que la dieta carente de proteínas era adecuada en todos los demás nutrientes.

A los 15 días de consumir la dieta aproticica Ios signos de depleción proteica eran más evidentes, de forma que elegimos este tiempo para utilizar el modelo animal. Los parámetros principales medidos en estas ratas se muestran en la Tabla 2 .

Gran importancia en el diseño de los experimentos posteriores tuvo el excelente trabajo publicado por Roheim, Miller y Eder (23) acerca de los factores que inciden en la liberación de lípidos, especialmente triglicéridos, al medio de perfusióa por hígados de rata perfundidos. En breve, estos autores proveyeron sólida evidencia de que existe en el plasma de ratas normales un apopeptido, Jibre de lípidos, que actúa como sustrato en la sintesis especialmente de VLDL, vale decir, 


\begin{tabular}{lrr} 
& \multicolumn{1}{c}{ Normales } & Desnutridas \\
\hline $\begin{array}{l}\text { Peso corporal, g } \\
\text { Proteinemia, g/100 m1. }\end{array}$ & $\mathbf{7 5 , 0} \pm 2,3 \pm 0,6$ & $21,4 \pm 1,8$ \\
$\begin{array}{l}\text { Triglicéridos séricos, } \\
\text { m/100 ml. }\end{array}$ & $29,3 \pm 2,8$ & $18,0 \pm 1,8$ \\
$\begin{array}{l}\text { Triglicéridos hepáticos, } \\
\text { mg/g }\end{array}$ & $5.1 \pm 0,7$ & $17,6 \pm 2,4$ \\
\hline
\end{tabular}

* Media \pm ES.

Tomada de la ref. 24: Por cortesía del Editor. J. Nutr.

proporcionando la matriz proteica de la lipoproteína. Aún cuando este apopeptido no había sido aislado $\rightarrow$ tampoco to ha sido hasta la fecha - - una preparación muy cruda de plasma que to contiene servía adecuadamente para utilizarla en nuestros estudios. Es así como pudimos comprobar que la inyección de esta preparación cruda, libre de lípidos, produce, en ratas con hígado graso debido a depleción proteica, un marcado aumento del nivel de triglicéridos circulantes (Fig. 3). No sólo observamos este efecto en las ratas con depleción proteica sino que la inyección de esta preparación cruda de apoproteína indujo una mayor incorpo. ración de un ácido graso marcado en tríglicéridos séricos (Tabla 3 ) y explicable en su totalidad por la incorporación de la marca en triglicéridos de la fracción VLDL (Tabla 4 (24). Estos resultados fueron interpretados como un aumento de la síntesis de VLDL inducido por la inyección del apo. peptido de la lipoproteína, y se concluyó que en las ratas depletadas de protcínas, y probablemente también en el kwashiorkor humano, la disponjbilidad del apopeptido es limitante para la síntesis de VLDL.

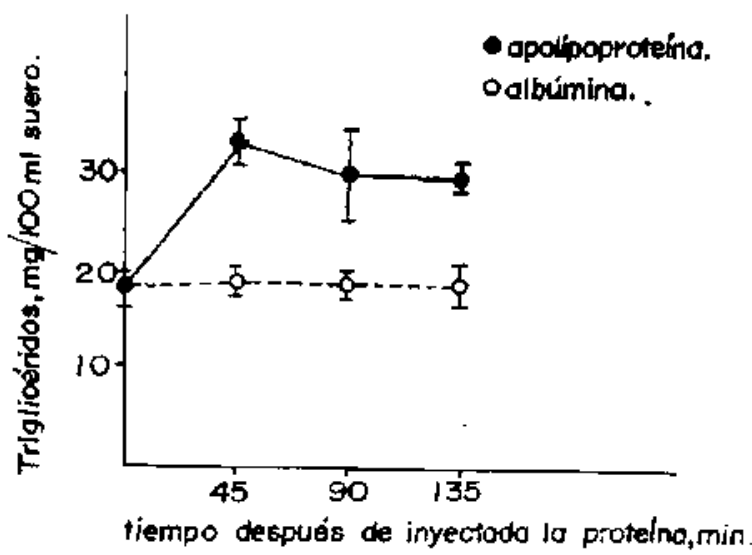

Figura 3.- Efecto de la apoproteina de la lipoprotelna de muy baja densidad sobre el nivel de triglicéridos séricos en ratas con hígado graso debido a depleción protejca, El grupo de animales contral recibió albrimina isćloga en vez de apuproteína (línea interior). De la referencia 24 , por cortes(a del Edjtor, J. Nutr.
INCORPORACION DE ACIDO OLEICO -I - 131 EN TRIGLICERIDOS PLASMATICOS

El ácido oleico marcado se inyectó por vía intrathuscular a tiempo 0. A los $60 \mathrm{~min}$. se inyectó una fracción cruda de suero conteniendo la apolipoprotenía de VLDL ó albúmina. Las ratas se sacrificaron a los 150 minutos.

\begin{tabular}{|c|c|c|}
\hline Tratamiento & Normates & Desnutridas \\
\hline Apolipoproteina & $18.176 \pm 2.873$ & $35.417 \pm 4.665$ \\
\hline Albúninina & $29.982 \pm 7.900$ & $9.335 \pm 2.000$ \\
\hline P. & 0,10 & 0.05 \\
\hline
\end{tabular}

TA B L A 4

INCORPORACION DE ACIDO OLEICO -I- IBI EN TRIGLICERIDOS DE VLDL SERICA EN RATAS NORMALES

\begin{tabular}{|c|c|c|c|}
\hline Tratamiento & $\begin{array}{c}\text { Triglicéridos } \\
\text { totales cpm/ml }\end{array}$ & $\begin{array}{l}\text { Triglicéridos en } \\
V \mathrm{LDL}, \mathrm{cpm} / \mathrm{ml}\end{array}$ & $\begin{array}{c}\text { Total } \\
\text { VLDL }\end{array}$ \\
\hline Apolipoproteína & 4.220 & 4,360 & 1,03 \\
\hline " & 7.900 & 8.140 & 1.03 \\
\hline$"$ & 6.450 & 7.670 & 1,18 \\
\hline Albúmina & 21.800 & 13.300 & 0,61 \\
\hline$"$ & 10.200 & 7.020 & 0,69 \\
\hline$"$ & 12.600 & 10.420 & 0,83 \\
\hline
\end{tabular}

Los efectos mencionados más arriba, sin embargo, no se observaron en ratas normales, en las que un factor distinto de la disponibilidad de la apoproteína sería el limitante para la síntesis de VLDL.

Concluyente y alentador como puede ser el resultado de los experimentos descritos en ratas, aparentemente enmascararon en esa oportunidad otros factores que inciden en el metabolismo de lípidos en la desnutrición proteica y en general, en la respuesta del animal a la depleción proteica especialmente en lo que se refiere a la infiltración grasa del hígado. En efecto, experimentos posteriores han demostrado que en ratas con bajo peso corporal al momento de iniciar la administración de la dieta carente de proteínas, la incidencia de hígado graso al final del período experimental es considerablemente menor. En los casos extremos, las ratas son incapaces de desarrollar hígado graso. (Fig. 4). En estas últimas ratas, que debían su bajo peso a una infección pulmonar, pudimos observar que la síntesis de triglicéridos en el hígado está marcadamente disminuida, lo que explicaría la ausencia de hígado graso (Tabla 5). 


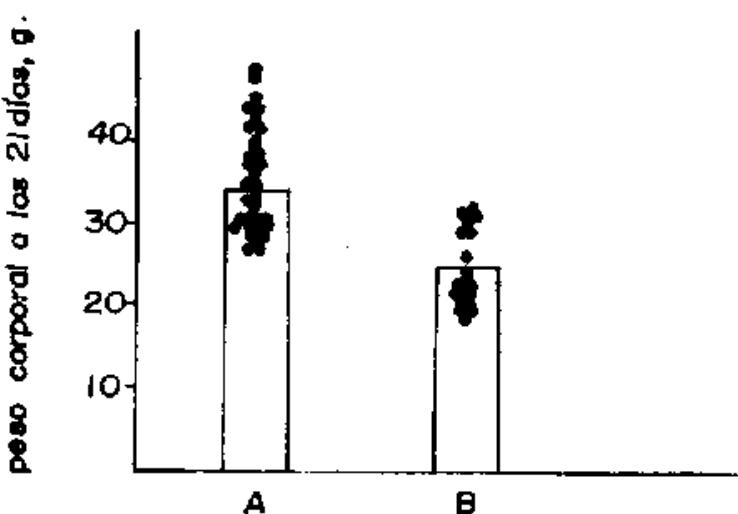

Figura 4.- Relación entre el peso de las ratas al momento de empezar la depleción protcica (destete) y su capacidad par: desarroliar higado graso. Grupu A: ratas cun hítado graso. brupo B.: tatas sin bígudo graso. Ambos grupos ingirieron una clieta apoproteica durantc 15 dias.

T A B L A 5

INCORPORACION DE ACIDO OLEJCO -I-I3I EN TRIGLICERIDOS HEPATICOS EN RATAS

Las ratas normales y de bajo peso se seleccionaron 10 min. después de la inyección intravenosa de ácido oleico - I- 131 .

Los lípidos hepáticos se fraccionaron por cromitografía en ácido silícico.

\begin{tabular}{cccc}
\hline Ratus & Normales & Bujo peso & $\begin{array}{c}\text { Baio peso y } \\
\text { depleción } \\
\text { proteica }\end{array}$ \\
\hline $\begin{array}{c}\text { Triglicéridos hepáticos, } \\
\text { mg/g }\end{array}$ & 5,1 & 2,1 & 1,4 \\
$\begin{array}{c}\text { Incorporación de marca, } \\
\% \text { de la dosis }\end{array}$ & 2,4 & 0.7 & 0,49 \\
\hline
\end{tabular}

Generalmente se insiste en que cl kwashiorkor y cl marasmo son los extremos entre los cuales hay una gradiente con una variada gama de signos clínicos y bioquímicos. Es probable que los resultados obtenidos en estas ratas desnutridas antes de comenzar la depleción proteié ayudan a dilucidar los factores que inciden en la ocurrencia de cuadros intermedios de desnutrición infantil. En este sentido podemos también señalar la significativa relación existente entre nivel de triglicéridos circulantes $y$ edad de pacientes con kwashiorkor que presentan hígado graso (Fig. 5). Con estos antecedentes, es comprensible que se hayan encontrado algunos cuadros de metabolismo de lípidos distintos de los descritos hasta ahora en pacientes pon hígado graso debido al kwashiorkor. Así, Coward y Whitehead, en Sudaffrica (25) informan que algunos de sus pacientes con kwashiorkor presentaron, al ingreso al hospital, niveles elevados de VLDL plasmática. En un estudio realizado en

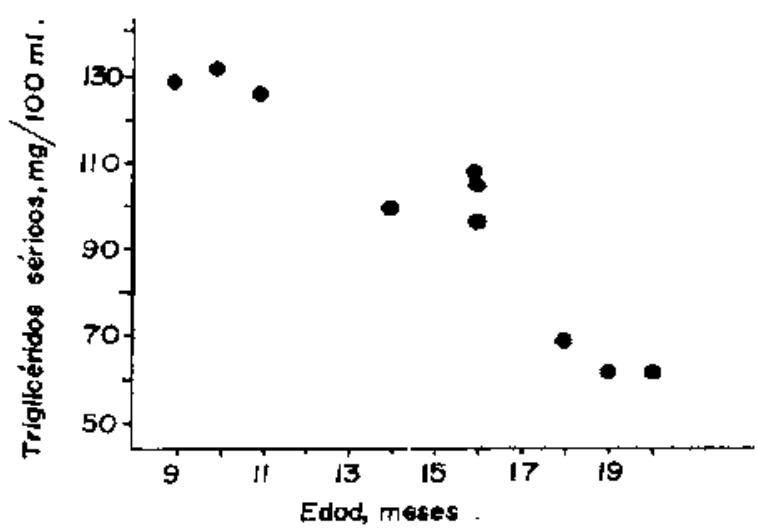

Fjgura 5. Relación entre el nivel de triglicéridos plasmáticos en ayunas y lá edad de pacientes jamaicanos con kwashiorkor.

Dantes del trotamiento después de recuperodos

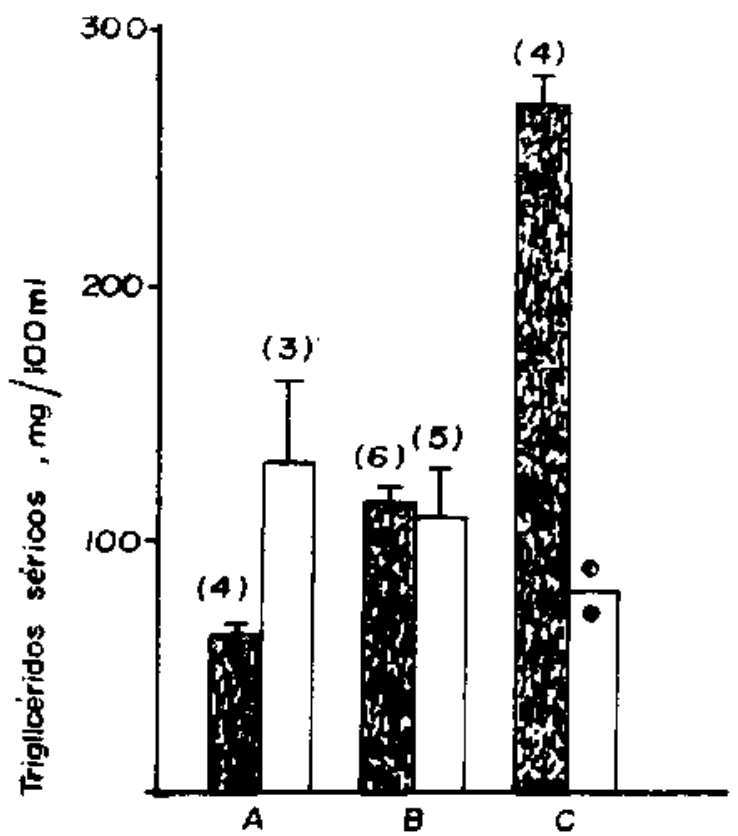

Fígura 6. Nícles de arigliććridos plasmácicos en ayunas en pacienses famaítanos con kwashiorkor antes y después del tratanientè. Las 3 grupos A, B, y C. Se dividicron arbilrariamento de acueido ; si los niveles subicron. se mantuvieron o bajaron lespués del vatamiento.

Jamaica (26) se estableció que, efectivamente hay tres grupos de pacientes en lo que respecta al nivel de triglicériodos plasmáticos antes del tratamiento, que presentan niveles bajos, como los ya descritos, niveles normales y niveles altos (26) (Fig. 6). Las causas de estos cuadros poco corrientes no están aún dilucidadas.

Otro factor que tiene también incidencia en el metabolismo de lípidos, y por ende, sobre los resultados de observaciones y experimentos en este 
canpo, es el nivel de lípidos de la dieta. La respuesta dol vive] to triglicéridos plasmáticos a cambios jel conterido de lípidos dietacios entre 25 y $60 \%$ de las c:lorías es muy rápida y marcada, como huthos cstablecido tanto en pacientes recuperados de desnutreción infantil (Figura 7) (27) como cu voluntarios adultos normales (Tabla 6).

Parce evidente que la ingesta de lípidos debe tanbién ser consider:iuti cuando se fijan los niveles "normales" de triglicéridos circulantes.
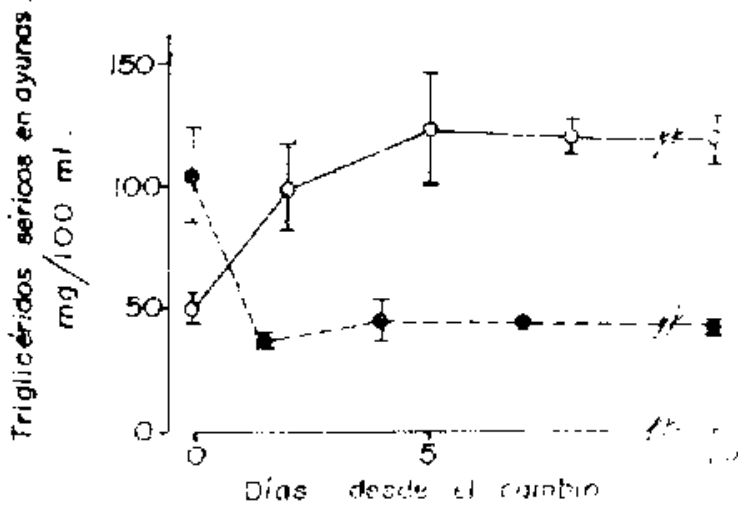

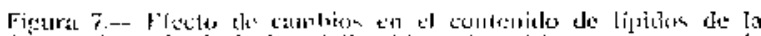

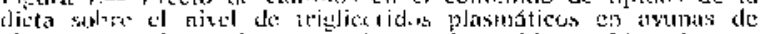

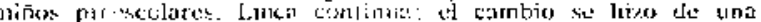

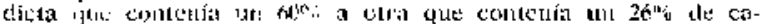

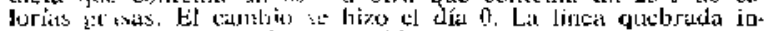

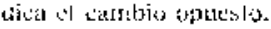

TA B L A 6

LFECTO DE LA INGCSTA DF TINHOOS SOBRE ILL NWEL DP TRIGLIERICOS SERICOS EN AYUNAS LN 5 VOLUNTAROS ADULIOS

Ent $:$ paréntesis se indica cl contenido de fípidos dt liti diet.. cumo porcentije de !aji calorías totiltes ingeridsis. Lis dietas se pieparaton utitizarato alimentos comunes, chidendo de gue primaran to; do alto contenido

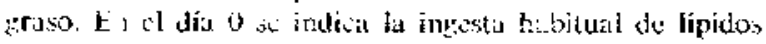
de los serjetos.

\begin{tabular}{|c|c|c|c|c|}
\hline $\begin{array}{l}\text { Dias en ta dista } \\
\text { crperimethital } \rightarrow\end{array} \rightarrow$ & $\begin{array}{c}\text { Trielice } \\
\theta\end{array}$ & los siri & $\begin{array}{c}m \alpha \\
2\end{array}$ & $\begin{array}{c}100 \mathrm{mi} \\
3\end{array}$ \\
\hline HIF & $\begin{array}{l}18 \times, 3 \\
\{20,6\}\end{array}$ & $\begin{array}{l}(0,5,0 \\
(70,6)\end{array}$ & $\begin{array}{l}89,0 \\
(67,9)\end{array}$ & $\begin{array}{l}78,1 \\
(70,4)\end{array}$ \\
\hline AS & $\begin{array}{l}135,0 \\
(39,6)\end{array}$ & $\begin{array}{c}93,1 \\
(75,4)\end{array}$ & $\begin{array}{c}74,1 \\
(71,5)\end{array}$ & $\begin{array}{l}70,6 \\
(71,8)\end{array}$ \\
\hline MS & $\begin{array}{l}114,0 \\
(35,1)\end{array}$ & $\begin{array}{c}71,5 \\
(70,1)\end{array}$ & $\begin{array}{c}49,5 \\
(73,0)\end{array}$ & $\begin{array}{c}67,0 \\
(74,2)\end{array}$ \\
\hline$C .1$ & $\begin{array}{l}\{00), 6 \\
(22,0\}\end{array}$ & $\begin{array}{l}44,8 \\
(65.9)\end{array}$ & $\begin{array}{l}40,9 \\
(69.6)\end{array}$ & $\begin{array}{c}67,4 \\
(73,6)\end{array}$ \\
\hline 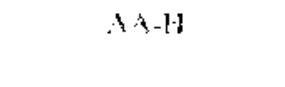 & $\begin{array}{c}56,6 \\
(43.2)\end{array}$ & $\begin{array}{c}39,6 \\
(65,9)\end{array}$ & $\begin{array}{c}41,6 \\
\left(f^{\prime}\right),(6)\end{array}$ & $\begin{array}{c}48,4 \\
(73,6)\end{array}$ \\
\hline
\end{tabular}

\section{AGRADECIMIENTOS:}

Este lrabajo hat sido financiado por grants del NIH HDO 3741-12 y de la Comisión de Investigación Cien. lífica, Facultad de Medicina, Universidird de Chile, pro. yecto (69-54) 25014262. Parte de ćl fue realizado en el Tropical Metabolism Research Unit, University of the West Indies, Jamaica, mientras H F. hacil uso de una beca del Wclcome Trust, Londres. La versión presentad. :qui incluye, con la gentil autorización de Raven Press, dato; presentados en el International Symposium on Dietary Lipids and Postnatal Development, Milán, octubre (c) 1972 (28) al que H. F. asistió grucias a un grant de lat Ford Foundation.

En divelsus aspectos inéditos de este trabaju cullabotaron los Dres. Oliver Brooke y Ann Ashworth Hile de la University of the West Indies, Jumajea, G. Mutebi, alumno de la misma Universicl: d, Mireya Fernández y Guillermina Szklatz de la Universid $x d \mathrm{~d} z$ Chile, estos últinos como parte de tesi: requeridas por sus planes de estudio. Los Profeseres J. C. Waterlow (1.ondon School of Hygiene ard Tropical Medicine) G. A. O. Aleype (University of the West lndies) y los Dres. Duvid Piecu y Dougla; Kerr (Tropical Metabolism Kuwetrch Unit. Uativersity of the West Indies) han aportudo valiosals sugerencias.

Tambićn en aspectos inéditos del trabajo prestaron valio colaboración técnicit Carmen Amos (Jamaica) y L. Salinas (Universidad de Chile).

\section{REFERENCIAS}

1.- $C_{\text {. } t: S t m}$ L. A. Determination of serum triglycerides 3. Atherosd Rts. 3: 334, 1963.

2.-Bront: Sithurt B. In Recent Advance in human Nurrition by J. F. Brock. p. 182 Ed. Churchill, London 1961.

3.- Srithelei, H. E. \& Hansen J. D. L. Studies en Fat metubolism in kwashiorkor $\mathbf{U}$ Strum polyunsatmated Falty acides Am. J. Clin. Nutr, 9: 735, 1961.

4.-. Mac Domald I., Hensen J. D. L. \& Bronte Stewart B. Liver depot and serum lipids during early recovary from kwashiorkor Clin. Sci. 24: 55, 1963.

5.-- Waterlow J. C. Fatty liver disease in Infants in the British West Indies. Medical Research Coucil, Special Report Series No 263, London, 1948.

6.-Chattcrice K. K, and Mukherjee K. L. Phospholioids of the liver in children suffering from proteincalorie undernutrition. Brit, J. Nutr, 22: 145, 1968.

7.-- Schawarle R. \& Dean R. F. A. The serum lipids in kwasholkor J. Trop. Pediat, 3: 23, 1957. 
8.- Lewis B, Hatsen J, D. L. Wittman W. Krut L. H. \& Stewart F. Plasma free fatty acids in kwashiorkor and the pathogenesis of the pathogenesis of the fatty liver. Am. J. Clin. Nutr. 15: 161, 1964.

9.-Flores H., Pak N., Mac'cioni A., \& Monckeberg F. Lipid Transport in kwashiorkor. Abstracts of the 37th. Annual Meeting of the Society for Pediatric, Research, Abril 1967, Atlantic City, U. S. A. p 143.

10.- Trustedl A. S. Hansen 1. D. L., Watson C. E. \& Wannenburg $P$. Relation of serum lipids and lipiproteins to fatty liver in kwashiorkor. Am. J. Clin Nutr. 22: 568, 1969.

11.- Fietcher $K$. Observations on the origin of livar fat in infantile malnutrition. Am. J. Clin. Nutr. 19: 170, 1966.

12. - Lewis B., Wittman W., Font L. H. Hanse't J. D. L. \& Brech J.F. Free fatty acid flux through plasma in protein-malnutrition of infants. Clin. Sci. 30: $371,1966$.

13.-Rao K. S. J. \& Prasad P. J. K. Serum triglycerides and non-esterified fatty acids in kwashiorkor. Am. J. Clin. Nutr. 19: 205, 1966.

14.-Hadden D. R. Glucose frec fatty acid and iusulin interrelations in kwashiorkor and marasmos. Lancet ii: $589,1967$.

15.- Milner R. D. G, Metzbolic and hormonal responses to glucose and glucegon in patients with infantile malnutrition Pediat. Res. 5: 33, 1971 .

16.- Flores H., Pck N., Maccioni A., \& Monckeberk $F$ Lipid Transport in kwashiorkor. Br. J. Nutr. 24 1005. 1970 .

17.- Monckeber $F$. Altetaciones bjoquímicas en la desnutrición Infantil, Nutr. Bromatol. Toxicol, 5: 31 , 1966.

18.- Monckeberg F. Adaptation to caloric and protein restriction in Infants. In Caloric deficiencies and protein deficiencies, p. 91. Ed. R. A. Mc Cance y Widdowson E. M. London J. and A. Churchill Ltd.
19.-Cravioto J., De la Pena, C. L. \& Burgos G. "Fat metabolism in chronic, severe malnutrition: lipoprotein in Children with kwashiorkor" Metabolism 8: 722,1959 .

20.-Heimberg M., Weinstein I., Dishmon $G$. \& Fried M. Lipoprotein lipid transport by livers from normal and CCLA poisoned animals. Am. J. Physiol. 209: 1053, 1965 .

21, - Schonfeld $G$. Changes in the composition of VLDL during carbohydrate induction in man. J. Lab. Clin. Med. 75: 206. 1970.

22.--Lies $R$. S. Immunological evidence for the presence of S. protein (apoprotein of B-lipoprotein) in normal and abetalipoproteinenic plasma. J. Lipid Res. 8: 396, 1967.

23,-Rohein F. S. Miller L. \& Eder $H$. A. The formation of plasma lipoprotein from apoprotein in plasma. J. Biol. Chem 240: 2994, 1965.

24. - Flores H., Sierralta $W_{\text {., }}$ \& Monckeberg F. Triglyceride transport in protein - depleted rats. J. Nutr. 100: $375,1970$.

25.-Coward, W. A. and Whitehead. R. G. Quantitative changes in serum proteins fractions during the development of kwashiorkor and in recovery.

Br. J. Nutr. 28: 433, 1972.

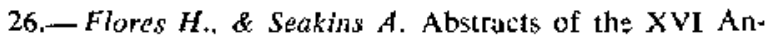
nual Mccting of the Standing Advisory Comnittee for Medical Research in the British Caribbean. Bridjetown. Barbados 1971, p. 14.

27.-Srakinc A. \& Flores $H$. Dietary fet and serum triglycerides. Abstracts of the XV Annual Meeting of the Standing Advisory Committee for Medical. Research in the British Caribbean. Kingsion, Jamaicia, 1970. p. 9.

28.- Flores H., Seakins A. and Monckeberg F. Mechanism of Fatty Liver in Infantile Malnutrition. En Galli G., Jacini C. and Pecile A, editors: Dietary Lipids and Postnatal Development, New York: Ritven Press, c. 1973. 